\title{
CITY@PATH: A COLLABORATIVE SMART CITY PLANNING AND ASSESSMENT TOOL
}

\author{
DIOGO CORREIA, JOÃO LOURENÇO MARQUES \& LEONOR TEIXEIRA \\ University of Aveiro, Portugal
}

\begin{abstract}
'The lack of strategic planning has increased urban pressure and accumulated traffic in cities. Smart Cities are replacing the short-time perspective with a long-term approach. The objectives align with city strategic goals, and citizens play an essential role in the decision-making process. High-level guidelines have emerged over the years to guide Smart Cities' vision and implementation. However, the lack of a tool that combines top-down and bottom-up approaches to help local policymakers plan and assess cities is still notorious. Moreover, this paper provides a methodology that allows the definition of structural priorities and contextual preferences while comparing policymakers' statements and citizens' opinions. Furthermore, this paper designs an approach to fill the existing gap and give policymakers a framework to monitor and measure their performance based on standard Key Performance Indicators and select relevant initiatives toward meeting the defined goals. This way, policymakers possess a tool that allows on the one hand, the standard comparison between cities and, on the other hand, the personalized comparison of their territory over time. Finally, a test case with the premise of improving city logistics is described to practically detail the guidelines of the proposed tool'.

Keywords: assessment, logistics, participatory development, smart city, transportation.
\end{abstract}

\section{INTRODUCTION}

More than half of the World's population now lives in urban areas [1]. By 2050, around 70\% of the population will live in cities and neighboring regions [2]. The mass migration to the cities will increase the number of densely populated areas, further complicating urban mobility and logistics [3]. Rapid urbanization also harms the environment. Although cities occupy $2 \%$ of the planet, they already account for $60 \%$ to $80 \%$ of energy consumption and $75 \%$ of carbon dioxide emissions. Increased traffic, pollution, waste and energy costs continue to present a growing threat to human health and city's sustainability [4].

Urban planning defines the rules of land usage to maximize economic development, with concerns to a high quality of life, wise management of natural resources and efficient operation of infrastructures [5], [6]. Smart Cities are an innovative view of urban development [7], [8] The concept from its origin advocated new policies for urban planning [9]. Nevertheless, urban planning has neglected social and sustainable practices by promoting private car usage [10]. Nowadays, policymakers' tendency to return city centers to citizens can be explained by the cultural misrepresentation noticed mainly because of tourism and associated economic activities. These increased inequality and housing unaffordability to inhabitants. Several authors refer to the need to restudy the concept of modern urban planning since it led to unsustainable urban trends [11], [12].

In addition, Covid-19 pandemics accelerated the necessity to re-think cities. Moreno et al [13] noted the need to assist citizens with closer public services, who proposed a '15-Minute city' conceptual approach to help policymakers to reflect on the strategic vision for their cities. In a nutshell, the four-dimensions concept (density, diversity, digitalization and proximity) aimed to help plan cities toward the availability of essentials to inhabitants, by foot or bicycle, promoting citizens' quality of life and combat the need of car usage. The application 
of this concept allows access to services in an outbound way, considering the citizens' movement from their homes. However, the same can be considered for the inbound transport of goods to the citizen, using transport modes such as scooters, bikes and cargo bikes [14].

The new paradigm of fulfilling citizens' real-time needs will represent a significant effort of urban planners and policymakers. Thus, it will require closer collaboration with citizens and the remaining stakeholders to plan the city accordingly. Traditional decision-making models do not allow the implementation of co-creation processes. Existing participation can sometimes have an opposite effect, as they do not mirror the majority's will because of the poor representativeness of the sample.

Smart Cities are replacing the short-term perspective to a more sustainable and long-term sustainable approach where objectives are aligned with the city's strategic goals. Municipalities are increasingly adopting open governance and promoting citizens' interaction by creating programs for a more efficient, transparent and collaborative environment [15], aligned with the noticed evolution of the Smart City concept.

Nevertheless, Smart city scholars are not the first to consider the role of citizens in policymaking. The discipline of development geography has been the first to address these and consider the citizens' role in development initiatives in the Global South [16].

The debates in this discipline can be subdivided into three main phases. Top-down interventions with very little involvement of the people marked the first phase, which happened in the post-World War II (WWII) decades [17]. This phase is often referred to as the Washington Consensus [18]. In the second phase, there was a need to involve the people affected by policies in their development [19]. It was also seen as a way to empower the poor and marginalized by giving them a voice and recognition in the development process [20]. This led to the emergence of partnerships between international organizations and local non-governmental organizations. A third phase came as a critique of this move toward participation. Authors such as Cooke and Kothari [21] argued that it was not enough to involve citizens in the policymaking process. It was essential to ask who is being involved and in what way. This was not a critique of participation itself but rather specific ways of involving citizens [22]. Furthermore, a complex understanding of the local context is needed, which sees the power of human relations and the struggles and conflicting interests between individual communities and intra-community groups [16].

Moreover, although high-level guidelines have emerged to guide Smart Cities' vision and implementation, policymakers still stress to comprehend and translate them to a practical tool that helps them define the priorities and monitor their actions according to their local environment. Furthermore, it lacks a comprehensive methodology to help plan and assess cities. Frameworks that assist decision-makers in conceptualizing strategies and implementing solutions toward defined goals by bringing together the various stakeholders, provide greater collaboration represent excellent tools [23], [24].

Thus, this paper aims, on the one hand, to provide a tool for the comparison among cities of their Smart City performance and, on the other hand, the regular cites' assessment to select and define an operational action plan to achieve their goals.

Therefore, after reviewing the literature on the transportation issues within cities and presenting the background on Smart Cities evolution and existing frameworks, this paper details a methodological planning and assessment approach rooted in the findings of previous studies. Ultimately, a test case on city logistics is addresses to allow a practical understanding of how the proposed methodology can be applied. 


\section{TRANSPORTATION ISSUES WITHIN CITIES}

The urban population growth caused an increase of goods transportation in the city center, impacting traffic congestion, the environment and energy consumption. Urban freight transport is influenced by lands usage distribution within cities. Warehouses throughout the years moved from the city centers to metropolitan areas due to the land costs and availability, meaning more considerable traveled distances and increasing number of vehicles [25]. Moreover, urban logistics is one of the most resource consumer and greenhouse gas emission existing activities, challenging cities' sustainability [5]. It is a primary cause of congestion in cities representing between $8 \%$ and $18 \%$ of urban traffic, at the same time that road capacity is decreased by $30 \%$ because of pick-up and delivery services [26]. Although goods transport is responsible for $14 \%$ of the vehicle kilometers, $19 \%$ of energy use, and $21 \%$ of $\mathrm{CO}_{2}$ emissions in urban areas, city logistics needs are often neglected in urban planning [27].

E-commerce, especially in the case of business-to-consumer (B2C), represents a significant challenge in urban logistics [28]-[31], increasing the difficulties of product distribution with direct impact on traffic congestion and accessibility [32] as well as environmental pollution and global warming [33]. Online sales are expected to increase to 5 US \$ trillion by the end of 2021 [34]. Moreover, parcel and express transports can be expected to grow exponentially, which will cause increased congestion and inflict the environment [35]. Several authors refer to the advantages of simultaneous and integrated proximity approaches between home delivery and client's pick-up [36], [37]. Furthermore, consumers' orders have an impact on logistics activities which interferes with the dynamics of cities. Wasteful travel time due to the significant variation of today's demand, the complexity of transportation networks, and increasing vehicle fleets are some of today's problems cities face [38]. Moreover, the mobility of people and transportation of goods neglected by urban planning are critical challenges for the future.

The above problems require newfangled urban thinking grounded in a holistic approach and long-term perspective. Urban sustainability's desire to balance environmental protection, economic development and social equality can only be achieved with the proper use and development of the land, environment, infrastructure, related ecosystem and human services.

The United Nations sustainable development objectives [39] led cities to consider decarbonization goals, adopting green and sharing policies with an additional focus on improving quality of life. On behalf of the Green Deal, the European Commission hopes to achieve carbon neutrality in the European Union by 2050. Sustainable Industry and Sustainable Mobility are among Green Deal policy areas [40]. Moreover, two goals are striving toward sustainable and smart mobility and mobilizing the industry to a clean and circular economy [41].

Nevertheless, strategic planning is still an abstract and unexplored idea in terms of design and operationalization [42]. Therefore, there is a need to create tools capable of supporting urban development decision-making [43] and assessing cities' progress toward specific goals [44].

\section{SMART CITIES PLANNING AND ASSESSMENT}

Smart Cities emerged in the 1990s to answer the challenges of urbanization and globalization and have evolved ever since. From the first technical perspective [45] to the understanding of technology as a means to achieve city's sustainability and improve the quality of life of their citizens [46], [47]. Nowadays, a new paradigm is emerging. The focus is on the inclusion of citizens in the co-creation and co-design of cities' processes and strategies [48] to improve the policies' chances of success [49]. Table 1 resumes the evolution of the Smart City concept. 
Table 1: The three Smart City stages.

\begin{tabular}{lll}
\hline Stage & Concept & Sources \\
\hline Smart City 1.0 & $\begin{array}{l}\text { A city that uses ICTs to collect data to improve } \\
\text { its critical infrastructures and services' } \\
\text { efficiency. }\end{array}$ & {$[51],[52]$} \\
Smart City 2.0 & $\begin{array}{l}\text { A city that starts with the human capital, } \\
\text { motivating citizens to create and flourish } \\
\text { their lives, using ICT to increase the quality } \\
\text { of life and the city's social, economic and } \\
\text { environmental sustainability. }\end{array}$ & {$[42],[44],[53]-[59]$} \\
Smart City 3.0 & $\begin{array}{l}\text { A city that uses ICT to promote citizen } \\
\text { engagement and active participation allows } \\
\text { continuous interactions. The strategy is } \\
\text { collaboratively created with citizens and relevant } \\
\text { stakeholders. }\end{array}$ & \\
\hline
\end{tabular}

Furthermore, Smart Cities have the responsibility to overcome inequality and social polarization [53]. In these matters, inclusiveness shall have a significant role in a Smart City's design thinking [63]. The decision-making process must promote inclusion and reduce social barriers [64]. The bottom-up participatory approaches play an essential role in assessing and developing Smart Cities [65].

Russo et al. [66] recall the smart city definition and guidelines evolution at an EU level. The European Parliament synthesizes international debate over Smart City concept by stating that including the participation of citizens and relevant stakeholders is a critical success factor. The Europe 2020 strategy was focused on three priorities [67]: Sustainable growth (low-carbon economy), smart growth (education, research and innovation) and inclusive growth (jobs and wealth). These are reflected on the three axes (Sustainability, Innovation and Quality of Life) of the Triangular Pyramid Trunk proposed by Correia et al. [68]. Nevertheless, the vertical of Smart Cities is considered under the umbrella of 'Smart Growth', leaving Sustainability and Inclusiveness aside [66].

Of the Smart Growth priority, two stakeholder advisory platforms emerged: European Technology Platforms and EIPs (European Innovation Platforms). The last aimed to bring public and private stakeholders together to accelerate research and innovation. Moreover, through EIP-SCC (EIP for Smart Cities and Communities), the Smart City assumed a relevant role [27]. The two governance bodies of EIP-SCC, high-level group and smart cities stakeholder platform, were responsible for defining rules and guidelines for the development of Smart Cities. The first joined high-level representatives from industry, academia and city administrations; the second aimed to be a collaborative tool for sharing knowledge and best practices. These can be found in the Strategic Implementation Plan [69], and the Operational Implementation Plan [70].

The guidelines cross (i) three specific vertical areas: sustainable urban mobility, sustainable districts and built environment, integrated infrastructures and processes across energy, ICT, and transport, with (ii) eight horizontal themes aggregated into three classes: Decisions (citizen focus, policy and regulation, and integrated planning and management), Insight (knowledge sharing, metrics, and indicators, open data and standards) and Funds (business 
models, procurement and funding). The intersection of vertical areas and horizontal themes constitutes 24 focus areas [27].

Strategic planning raises the challenge of integrating the needs for smarter urban environments with the policy strategies followed by local decision-makers in response to the existing weaknesses of the urban system. This raises the question of whether the produced decisions express citizens' preferences, and if the answer is positive, how [71].

Thus, in the breakdown of strategic plans, local decision-makers are challenged to adopt new approaches and instruments to answer complex, territorialized socioeconomic needs. The challenge is to transfer macro guideline scales to micro reality.

In addition, from the European Smart Cities Ranking [72] to other assessment indexes present in the literature, there is a lack of medium and long-term goals consideration [73]. Therefore, there is not a standard tool used by cities to monitor themselves continuously. International Organization for Standardization (ISO) and International Telecommunication Union (ITU) have played a leading role in defining standards for these matters. However, there is no tool capable of monitoring and assessing the city's performance toward specific objectives [77] nor contemplating citizens' points of view.

In terms of city assessment, the existing frameworks have been mostly used to rank the cities, mixing up different concepts, and not consider the evolution noticed in the Smart City concept. However, they present significant insights (see more at [68]). For example, Sharifi [78] concluded that assessment tools do not consider indicators' interlinkages and correlations as well as local needs and participatory approaches; Ahyenniemi et al. [59] demonstrated that Smart City assessment tools are focused on social aspects and the Sustainable Cities' on the environment; Huovila et al. [79] concluded that $90 \%$ of the key performance indicators (KPIs) from ISO 37120 were focused on Sustainability and the ITU 4902 had a purely ICT-enabled indicator orientation. In contrast, the remaining have an inadequate presence of these indicators [80]. Thus, it reinforces the relevance and the role of the citizens. Moreover, the objective approach shall be combined with a subjective perspective.

The following section considers the literature findings to provide a tool to assess and monitor Smart Cities' performance and help policymakers select and define relevant initiatives to answer urban challenges.

\section{PROPOSED SMART CITY ASSESSMENT AND PLANNING APPROACH}

Section 2 identified the existing transportation challenges caused by globalization and urbanization, where the environment will be impacted by the evolution of transportation (of passengers and goods) considering the decisions of policymakers and urban planners. Therefore, collaborative strategic planning is crucial to achieve sustainability and promote citizens' well-being. Nevertheless, Smart Cities' literature pinpoints the need for a methodology to help local policymakers realize the city's current state and define an action plan toward their goals.

Therefore, the following methodology is designed to contemplate the macro (structural) and micro (contextual) dimensions, to provide the chance of evaluating the territory, while enabling the development of different initiatives based on local priorities and preferences. Based on the previously mentioned studies' conclusions, three axes were defined, considering the evolution of the Smart City concept [57], [81], [82] also mirrored in the priorities of Europe 2020 strategy [67].

Cities have the need to acknowledge their services, processes and systems and realize what can be optimized (where the resources are being misused). Thus, perform a self-assessment 
to build a strategic plan based on the solutions that can significantly impact the territory toward the defined strategic goals. To adequately address a Smart City strategy, it is necessary to measure city's performance overtimes. Therefore, in policymaking, three different assessment moments are vital [83], as shown in Fig. 1:

I. Before starting the process (Ex Ante) - calculating the values for the KPIs to define the strategic goals and define the relevant initiatives.

II. Ongoing assessment (Monitoring) - current assessment of the implemented solutions and their impact on the defined targets.

III. After the conclusion of a specific initiative (Ex Post) - a comparison if the implementation met the expected results toward the city strategic goals.

Following Correia, Teixeira and Marques [68], the primary KPIs will be collected from ISO 37120, ITU 4901 and Mercer's annual quality of life survey.

Two axes shall be considered with two different approaches each:

- The vertical is divided in (i) top-down approach - objective statistical analysis. Consideration of political guidelines explained in strategic planning documents, and public policy programs; (ii) bottom-up approach - which gives particular emphasis to the citizen, on the development of composite indicators and in the definition of initiatives toward the improvement of people's living conditions.

- The horizontal axis combines the (i) structural approach (classical) - measurement of the standard Smart City performance through a set of indicators, comparable between cities; and (ii) the contextual (operational) approach - contemplates each territory's priorities to personalize the understanding of the Smart City action plan in each context, comparable in different moments.

Moreover, the axes can be resumed and organized into four quadrants as they are represented in Fig. 2.

The horizontal and vertical axes have the objective of combining bottom-up and top-down approaches to:

(1) Monitor and measure the performance - To reduce the number of KPIs, there must be analyzed existing relationships. The focus shall be given to the variables that significantly influence the overall statistical representativeness, avoiding redundancies. Thus, through factor analysis, the fundamental dimensions and KPIs of each axis should be returned. Factor analysis can be complemented with the creation of a composite indica-

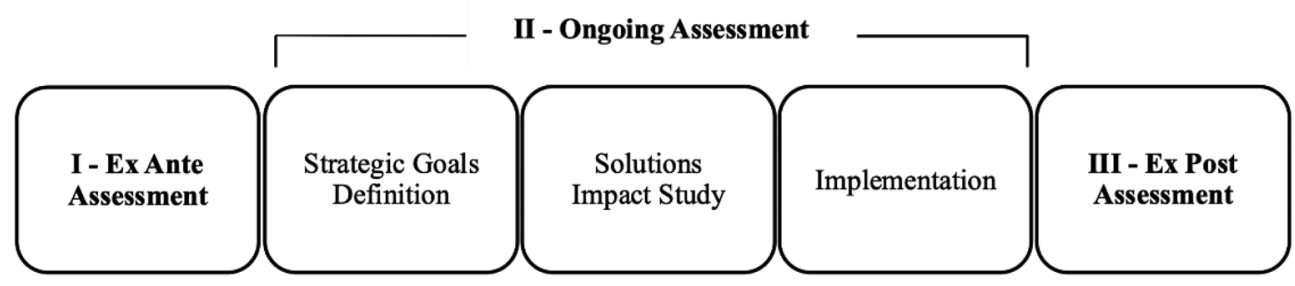

Figure 1: Assessment overview. 


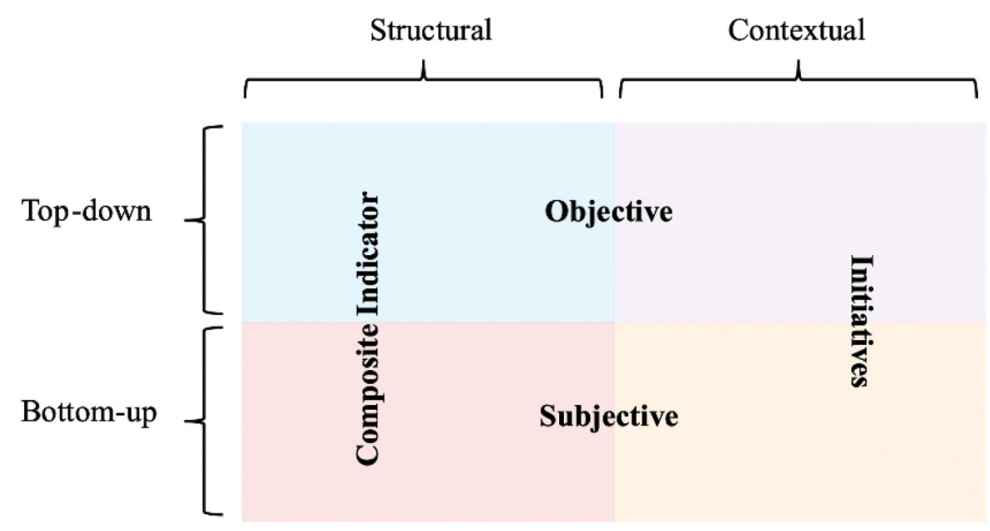

Figure 2: The quadrants of the Smart City Assessment Tool.

tor by aggregating the independent factors. Moreover, on the one hand, a top-down composite indicator can be obtained based on objective statements - aggregated by assigning a weight to each factor according to the proportion of the explained variance in the data set - and, on the other hand, a subjective composite indicator - through the factors' level of importance given by citizens.

(2) Select and define relevant initiatives - Existing priorities are crucial to select the initiatives that help the city achieve the established goals. The reasoning starts from the same primary KPIs or those from the Factor Analysis (green color connection in Fig. 3). As mentioned before, the participation of citizens is vital to Smart Cities. The inclusion of the citizens will also be done on behalf of the priorities' definition. In the top-down approach, political statements and directory plans will base the priorities of policymakers. At the same time, subjective data will be gathered from citizens to define the priority (weight) for each KPI. This way, it is preserved that citizens are different among cities and, therefore, have different priorities. The priorities of citizens (bottom-up) can be evaluated through a Likert scale or peer-to-peer pairwise comparison. Only the variables mirrored in the composite index and their grounded factors are contemplated for evaluation.

First, the confrontation of the KPIs' results with the study and comparison of their importance to the local community, and second, the priorities for the territory will give policymakers the knowledge of the city goals, how far they are from reaching them, and the KPIs that will deserve the attention of the action plan. Thus, the difference between the evaluation of citizens (bottom-up) and policymakers (top-down) can be understood as the fulfillment deviation. This should enhance the definition of an action plan with clear goals to overcome this difference.

Ultimately, the definition of the implementing policies can be carried out contemplating the multi-criteria decision analysis (MCDS) [84] definition of criteria to achieve the intended goals - or the data envelopment analysis (DEA) [85] - input management to maximize the efficiency of outputs.

Regardless of the chosen method, the difference between the current KPIs results and their goals shall be the starting point for procurement solutions that can improve their current values. A single digital marketplace can be set up where the entities shall promote their 
solutions and case studies. Cities shall study each option to improve the KPIs value and the expected return on the investment. Moreover, third parties' developments can also answer the existing challenges through partnerships, where local governments do not act in isolation but in collaboration with the stakeholders.

Furthermore, a solution's impact must be calculated with the expected KPI improvement toward the defined goals. Therefore, a reverse engineering process must be carried out to understand which solutions should be implemented. Additionally, the target audience of a specific policy or initiative must be measured and compared. Each city shall assess the representativeness (percentage of people) of each social group (or just the minorities' inclusion) reached with that initiative. It will allow understanding the population's number and the social groups that are not being considered.

The assessment cycle ends with the measurement of the policy's impact based on the new KPI value. The policy's impact evaluation shall be calculated according to the measurable outcomes, their contribution for the final result, which groups were affected, the influence of the context, and reproduction [83].

In summary, the methodology that will guide, on the one hand, the comparison among cities and, on the other hand, cities' assessment to select and define an operational action plan is detailed in Fig. 3.

\section{CITY LOGISTICS TEST CASE}

Test cases are usually executed to test every requirement on the level of software units, software integration and system tests [86]. Thus, this work conceptualizes the initial guidelines to build a dedicated software. Moreover, as it was intended to conceptualize a generic tool, this section describes the needed steps to adapt it to any use case.

The goal of the proposed methodology (Fig. 3) is to monitor the city's current state while planning the actions toward the priorities defined by citizens and policymakers.

Among the 24 cross working areas of the European guidelines identified above, the city logistics case derives from the intersection between sustainable urban mobility (vertical area) and integrated planning and management (horizontal theme) [27]. Furthermore, as stated before, mobility and goods transportation have a significant impact on city dynamics. Thus, this test case has the premise of a city that needs and wants to prioritize the actions that improve the transportation network and avoid using the private car (assuming that the KPIs results are poor, and it is a citizens' priority). At the same time, optimize and promote proximity last-mile solutions to reduce the number of vehicles circulating.

Therefore, the methodological procedure must be considered as follows. The first steps define the importance of each KPI for the city strategy, which is directly associated with the local understanding of what a Smart City shall be (macro-level). From step 4 onwards, are mirrored the local priorities (micro-level), which will be the mobility and city logistics in this test case. Therefore, the first steps are standard. The step 4 is where the priorities are defined. This test case will be based on the related KPIs to city logistics and urban transportation.

Step 0: Identification of a territory and calculation of the KPIs of each axis.

Step 1: Principal Component Analysis (Factor score) on the KPIs for each axis. Consider only components with greater representativity (significant).

Step 2 [Top-down structural]: The objective Composite Indicator of Smart Cities is the result of the disaggregated average of the three axes results. 


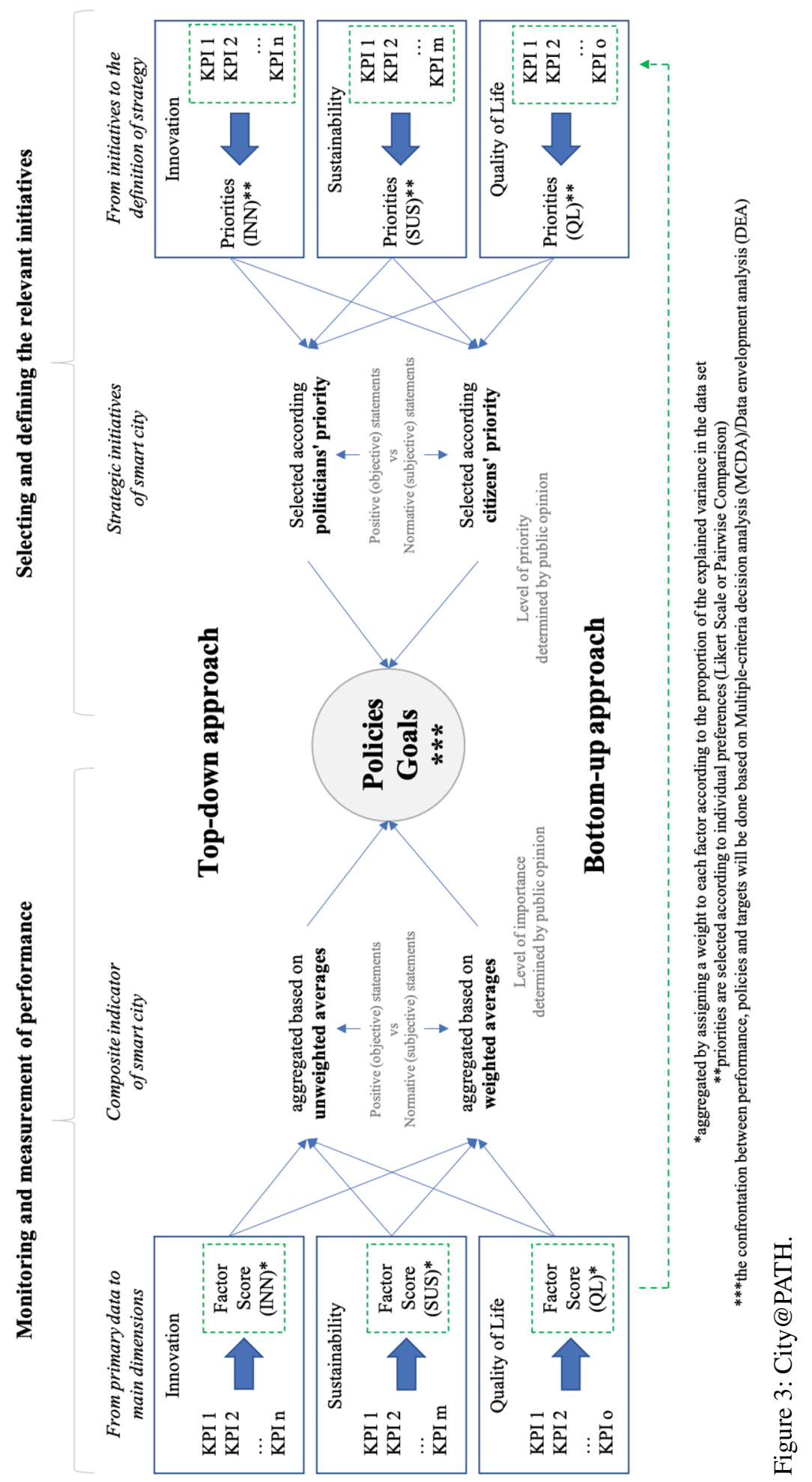


Step 3 [Bottom-up structural]: The subjective Composite Indicator of Smart Cities is the result of the aggregated average based on weights average. Weighting is carried out to each axis by citizens. This importance level can also be given to each of the KPIs.

There is no direct aggregation between bottom-up and top-down evaluations. The top-down allows the possibility of making standard comparisons between cities and within the same city at different times since there is no allocation of weights. The bottom-up evaluation has an associated subjective component depending on the given weights by citizens, thus making each city unique. The comparison between objective and subjective results will allow assessing the relationship between policymakers and the opinion of citizens. Thus, it allows the understanding of whether citizens value the variables with higher performance (best results). On the other hand, the city's strategy is inaccurate because the objective composite value is higher than the subjectively weighted average. The analysis of both perspectives will allow the definition of the city's strategic goals, since the aim will be to understand the disparity of top-down approach regarding the bottom-up to define an action plan with clear objectives toward improving the variables that have poor results or are prioritized by citizens.

Step 4 [Top-down contextual]: Study of the priorities. These can be obtained according to the worst KPIs results or by political orientations.

Step 5 [Bottom-up contextual]: For each axis is asked the opinion of citizens about the priority of their KPIs. Citizens allocate the weights through the Likert Scale or Pairwise Comparison.

Because this test case has the premise of a city whose priority is to improve urban logistics (KPIs with the worst results or valued the most by citizens), the focus would be on the following KPIs:

- Kilometres of public transport system per 100000 population

- Annual number of public transport trips per capita

- Percentage of commuters using a travel mode to work other than a personal vehicle

- Kilometers of bicycle paths and lanes per 100000 population

- Greenhouse gas emissions measured in tonnes per capita

$-\ldots$

Step 6: Once the KPIs are identified, a search for solutions (possibly with scientific evidence) about the hypothesis that can positively impact the KPIs toward the defined goals should be carried out. These solutions can also emerge from the discussion with the community. The definition of the action plan will be based on the confrontation between the goals and the impact of solutions based on MCDA or DEA.

The possibility that citizens can view the top-down information while giving their opinion or, at least at a final stage, may allow a better perception and knowledge of the matter, which will contribute to the community's discussion and engagement. 


\section{CONCLUSIONS, LIMITATIONS AND FUTURE WORK}

Urbanization and globalization have increased urban pressure, which affected urban mobility and the environment. These problems arose from the disregard of strategic planning. Concepts as the '15-minute city' have emerged to highlight the importance of urban planning, contemplating the disposal of essential services close to the citizens to combat the need to use the private car.

This paper crossed the literature of development geography and Smart Cities to clarify the existing gap on participation schemes, which is mainly because high-level guidelines cannot be translated into practical steps that consider local contexts. That can be acknowledged on European Commission guidelines and the strategic and operational plans promoted by the EIP-SCC. It lacks the ability to policymakers adjust the framework to their community needs and monitor their strategy toward co-defined priorities.

Moreover, this paper proposed combining top-down and bottom-up approaches based on the collaboration between decision-makers and citizens to providing a framework capable of monitoring Smart Cities and support decision-making by addressing specific priorities. The tool allows the overview of city's current state and the understanding of the most critical KPIs to establish strategic goals and look for solutions to improve their results.

Besides stating the city's current state concerning the Smart City concept phase, the objective was to allow policymakers realize how far they are from achieving the goals and satisfy citizens' wishes. With this tool, policymakers can understand their citizens' preferences profile, allowing better planning, investment and resource allocation. The continuous performance assessment is crucial to guarantee that cities are going toward the defined goals.

The city logistics test case explained how the framework could be applied to any use case (priority). The methodology helps structure cities' design thinking and strategy definition through continuous evaluation, comparison between territories and contemplation of citizens' opinions. Moreover, depending on current opportunities, (mainly at the financial support level) priorities can be changed. Therefore, the exercise should be reviewed in a defined time-space to align expectations with the reliability of outputs.

As a limitation, the framework rationale starts from the comprehension of three distinct axes - Sustainability, Innovation and Quality of Life - based on a previous study that is not yet widely adopted in academia. Nevertheless, the methodology can consider other axes and associated KPIs. The paper's contribution is on the definition of the path to evolve citizens and policymakers in decision-making and allow the creation of a tool that considers their opinions as equal for the understanding of what a Smart City is and the priorities of the territory. The importance of the KPIs themselves can also be studied. Weights should be reviewed periodically because the assigned importance may change over time. Considering the city's evolution, the circumstances of the moment, and the context in which the changes were advocated may be essential to understand the reasons behind.

As future work, it is vital to study citizen's participatory development and engagement methods of specific groups in practice. Dashboards and software solutions can be created with the present research to provide user-friendly interfaces to plan and assess cities.

\section{ACKNOWLEDGMENT}

This work is an output of the research project DRIVIT-UP - DRIVIng forces of urban Transformation: assessing Public Policies, Grant/Award Number: POCI-01-0145-FEDER-031905; It was also developed within the research unit on Governance, Competitiveness and Public Policy (UIDB/04058/2020)+(UIDP/04058/2020), and the Institute of Electronics and Informatics Engineering of Aveiro (UIDB/00127/2020), both funded by national funds through FCT - Fundação para a Ciência e a Tecnologia. 


\section{REFERENCES}

[1] H. Chourabi et al., Understanding smart cities: An integrative framework. Proc. Annu. Hawaii Int. Conf. Syst. Sci., no. July 2014, pp. 2289-2297, 2012.

[2] United Nations, World Urbanization Prospects. 2015.

[3] 2012 OECD, OECD (2012), OECD Environmental Outlook to 2050, OECD Publishing. 2012.

[4] P., Neirotti, A., De Marco, A. C., Cagliano, G., Mangano and F., Scorrano, Current trends in Smart City initiatives : Some stylised facts. Cities, 38, pp. 25-36, 2014.

[5] S. E., Bibri and J., Krogstie, Smart sustainable cities of the future: An extensive interdisciplinary literature review. Sustain. Cities Soc., 31, pp. 183-212, 2017.

[6] L. G., Anthopoulos and A. Vakali, Urban Planning and Smart Cities : Interrelations and Reciprocities Urban Planning : Principles and Dimensions. Lect. Notes Comput. Sci., 7281, pp. 178-189, 2012.

[7] A., Meijer and M. P. R., Bolívar, Governing the smart city: a review of the literature on smart urban governance. Int. Rev. Adm. Sci., 82(2), pp. 392-408, 2016.

[8] T., Nam and T. A., Pardo, Smart city as urban innovation. Proc. 5th Int. Conf. Theory Pract. Electron. Gov. - ICEGOV'11, p. 185, 2011.

[9] Harrison Colin and I. A., Donnelly, A Theory of Smart Cities, 91, pp. 399-404, 2017.

[10] P., Newman, T., Beatley and H., Boyer, Resilient cities: Overcoming fossil fuel dependence. Island Press, 2017.

[11] P., Gurstein and T., Hutton, Planning on the Edge: Vancouver and the Challenges of Reconciliation, Social Justice, and Sustainable Development. UBC Press, 2019.

[12] L., Adkins, M., Cooper and M., Konings, Class in the 21st century: Asset inflation and the new logic of inequality. Environ. Plan. A, 0,(0), pp. 1-25, 2019.

[13] C., Moreno, Z., Allam, D., Chabaud, C., Gall and F., Pratlong, Introducing the '15-Minute City': Sustainability, Resilience and Place Identity in Future Post-Pandemic Cities. Smart Cities, 4(1), pp. 93-111, 2021.

[14] F., Arnold, I., Cardenas, K., Sörensen and W., Dewulf, Simulation of B2C e-commerce distribution in Antwerp using cargo bikes and delivery points. Eur. Transp. Res. Rev., 10(1), 2018.

[15] L., Carter and F., Bélanger, The utilization of e-government services: Citizen trust, innovation and acceptance factors. Inf. Syst. J., 15(1), pp. 5-25, 2005.

[16] D., Correia, J., Feio, L., Teixeira and J. L., Marques, The Inclusion of Citizens in Smart Cities Policymaking: The Potential Role of Development Studies' Participatory Methodologies, in Distributed, Ambient and Pervasive Interactions, N. Streitz and S. Konomi, Eds. Springer Nature Switzerland AG, 2021.

[17] H. M., Mathur, Participatory development: Some areas of current concern. Sociol. Bull., 46(1), pp. 53-95, 1997.

[18] C., Gore, The Rise and Fall of the Washington Consensus as a Paradigm for Developing Countries. 28(5), 2000.

[19] D., Mosse, Authority, Gender and Knowledge: Theoretical Reflections on the Practice of Participatory Rural Appraisal. Dev. Change, 25(3), pp. 497-526, 1994.

[20] G., Mohan and K., Stokke, Participatory development and empowerment: the dangers of localism. Third World Q., 21(2), pp. 247-268, 2000.

[21] B., Cooke and U., Kothari, Participation: The new tyranny?, Zed books, 2001.

[22] S., Hickey and G., Mohan, Participation: from tyranny to transformation: exploring new approaches to participation in development, Zed books, 2004.

[23] Á., Oliveira and Margarida Campolargo, From Smart Cities to Human Smart Cities, in 48th Hawaii International Conference on System Sciences, 2015. 
[24] T., Shelton, M., Zook, and A., Wiig, The 'actually existing smart city'. Cambridge J. Reg. Econ. Soc., 8(1), pp. 13-25, 2015.

[25] L., Dablanc, Logistics Sprawl and Urban Freight Planning Issues in a Major Gateway City : The Case of Los Angeles. Sustain. Urban Logist. Concepts, Methods Inf. Syst., pp. 49-69, 2014.

[26] R., Nocerino, A., Colorni, F., Lia and A., Luè, E-bikes and E-scooters for Smart Logistics: Environmental and Economic Sustainability in Pro-E-bike Italian Pilots. Transp. Res. Procedia, 14, pp. 2362-2371, 2016.

[27] F., Russo, C., Rindone and P., Panuccio, European plans for the smart city: from theories and rules to logistics test case. Eur. Plan. Stud., 24(9), pp. 1709-1726, 2016.

[28] J. H. R., Van Duin, W., De Goffau, B., Wiegmans, L. A., Tavasszy and M., Saes, Improving Home Delivery Efficiency by Using Principles of Address Intelligence for B2C Deliveries. Transp. Res. Procedia, 12, no. June 2015, pp. 14-25, 2016.

[29] J., Visser, T., Nemoto and M., Browne, Home Delivery and the Impacts on Urban Freight Transport: A Review. Procedia - Soc. Behav. Sci., 125, pp. 15-27, 2014.

[30] T., Eiichi and K., Yasushi, Modelling Effects of E-commerce on Urban Freight Transport, in Logistics Systems for Sustainable Cities, E. Taniguchi and R. G. Thompson, Eds. Emerald Group Publishing Limited, pp. 135-146, 2004.

[31] V., Gatta, E., Marcucci, M., Nigro, S. M., Patella and S., Serafini, Public transport-based crowdshipping for sustainable city logistics: Assessing economic and environmental impacts. Sustain., 11(1), pp. 1-14, 2018.

[32] E., Morganti, L., Dablanc and F., Fortin, Final deliveries for online shopping: The deployment of pickup point networks in urban and suburban areas. Res. Transp. Bus. Manag., 11, pp. 23-31, 2014.

[33] R., Ducret, Parcel deliveries and urban logistics: Changes and challenges in the courier express and parcel sector in Europe - The French case. Res. Transp. Bus. Manag., 11, pp. 15-22, 2014.

[34] eMarketer, Global Ecommerce 2019, [Online]. Available: https://www.emarketer.com/ content/global-ecommerce-2019, 2019 [Accessed: 15-Aug-2020].

[35] E., Taniguchi, R. G., Thompson and T., Yamada, New Opportunities and Challenges for City Logistics. Transp. Res. Procedia, 12, June 2015, pp. 5-13, 2016.

[36] L., Zhou, R., Baldacci, D., Vigo and X., Wang, A Multi-Depot Two-Echelon Vehicle Routing Problem with Delivery Options Arising in the Last Mile Distribution. Eur. J. Oper. Res., 265(2), pp. 765-778, 2018.

[37] L., Zhou, X., Wang, L., Ni and Y., Lin, Location-routing problem with simultaneous home delivery and customer's pickup for city distribution of online shopping purchases. Sustain., 8(8), 2016.

[38] S., Lee, Y., Kang and V. V., Prabhu, Smart logistics: distributed control of green crowdsourced parcel services. Int. J. Prod. Res., 54(23), pp. 6956-6968, 2016.

[39] UN, Sustainable development goals, [Online]. Available: https://www.un.org/ sustainabledevelopment/sustainable-development-goals, 2018.

[40] EC, A European Green Deal, [Online]. Available: https://ec.europa.eu/info/strategy/ priorities-2019-2024/european-green-deal_en\#policy-areas, 2019. [Accessed: 21-Oct2020].

[41] European Commission, The European Green Deal, 2019.

[42] M., Angelidou, Smart city policies: A spatial approach. Cities, 41, pp. S3-S11, 2014.

[43] S., Zygiaris, Smart City Reference Model: Assisting Planners to Conceptualize the Building of Smart City Innovation Ecosystems. J. Knowl. Econ., 4(2), pp. 217-231, 2013. 
[44] S. P., Mohanty, U., Choppali and E., Kougianos, Everything you wanted to know about smart cities. IEEE Consum. Electron. Mag., 5(3), pp. 60-70, 2016.

[45] L., Mora, R., Bolici and M., Deakin, The First Two Decades of Smart-City Research: A Bibliometric Analysis. J. Urban Technol., 24(1), pp. 3-27, 2017.

[46] M., Tan, Creating the Digital Economy: Strategies and Perspectives from Singapore. Int. J. Electron. Commer., 3(3), pp. 105-122, 1999.

[47] M., Angelidou, Smart cities: A conjuncture of four forces. Cities, 47, pp. 95-106, 2015.

[48] A., Mainka, W., Castelnovo, V., Miettinen, S., Bech-Petersen, S., Hartmann and W. G., Stock, Open innovation in smart cities: Civic participation and co-creation of public services. Proc. Assoc. Inf. Sci. Technol., 53(1), pp. 1-5, 2016.

[49] S., Al-Nasrawi, A., El-Zaart and C., Adams, The Anatomy of Smartness of Smart Sustainable Cities: An Inclusive Approach. 2017 Int. Conf. Comput. Appl. ICCA 2017, pp. 348-353, 2017.

[50] R., Pérez-Delhoyo, H., Mora, R., Abad-Ortiz and R., Mollá-Sirvent, Social networks of sport and their potential in smart urban planning processes. Int. J. Transp. Dev. Integr., 4(1), pp. 62-74, 2020.

[51] R. E., Hall, B., Bowerman, J., Braverman, J., Taylor and H., Todosow, The vision of a smart city. 2nd Int. Life ..., 28, p. 7, 2000.

[52] C. Harrison et al., Foundations for Smarter Cities. IBM J. Res. Dev., 54(4), 2010.

[53] R. G., Hollands, Will the real smart city please stand up? Intelligent, progressive or entrepreneurial?. City, 12(3), pp. 303-320, 2008.

[54] Rios, ' The Smart City' Table of Contents. Development, 2008.

[55] A., Caragliu, C., del Bo, and P., Nijkamp, Smart cities in Europe. J. Urban Technol., 18(2), pp. 65-82, 2009.

[56] T., Chen, Smart grids, smart cities need better networks. IEEE Netw., 24(2), pp. 2-3, 2010.

[57] J. M., Barrionuevo, P., Berrone and J. E., Ricart Costa, Smart Cities, Sustainable Progress: Opportunities for Urban Development. IESE Insight, 14, pp. 50-57, 2012.

[58] P., Neirotti, A., De Marco, A. C., Cagliano, G., Mangano and F., Scorrano, Current trends in smart city initiatives: Some stylised facts. Cities, 38, June, pp. 25-36, 2014.

[59] H., Ahvenniemi, A., Huovila, I., Pinto-Seppä and M., Airaksinen, What are the differences between sustainable and smart cities?. Cities, 60, pp. 234-245, 2017.

[60] S., Van der Graaf and C., Veeckman, Designing for participatory governance: Assessing capabilities and toolkits in public service delivery. Info, 16(6), pp. 74-88, 2014.

[61] V., Albino, U., Berardi and R. M., Dangelico, Smart cities: Definitions, dimensions, performance, and initiatives. J. Urban Technol., 22(1), pp. 3-21, 2015.

[62] B., Trivellato, How can 'smart' also be socially sustainable? Insights from the case of Milan. Eur. Urban Reg. Stud., 24(4), pp. 337-351, 2017.

[63] D., Correia and J., Feio, The Smart City as a Social Policy Actor, in International Conferences ICT, Society, and Human Beings, 2020.

[64] B. N., Silva, M., Khan and K., Han, Towards sustainable smart cities: A review of trends, architectures, components, and open challenges in smart cities. Sustain. Cities Soc., 38, January, pp. 697-713, 2018.

[65] D., Hemment, M., Woods, V., Appadoo and L., Bui, Community Key Performance Indicators (Community KPIs) for the IoT and Smart Cities, 2016.

[66] F., Russo, C., Rindone and P., Panuccio, The process of smart city definition at an EU level. WIT Trans. Ecol. Environ., 191, pp. 979-989, 2014. 
[67] European Commission, Communication from the commission - Europe 2020. A strategy for smart, sustainable and inclusive growth, [Online]. Available: https://eur-lex.europa. eu/LexUriServ/LexUriServ.do?uri=COM:2010:2020:FIN:en:PDF, 2010 [Accessed: 04-Aug-2021].

[68] D., Correia, L., Teixeira and J., Marques, Triangular Pyramid Trunk: the Three Axes of the Smart City Assessment Tool. WIT Trans. Ecol. Environ., 241, pp. 79-90, 2020.

[69] European Commission, European Innovation Partnership on Smart Cities and Communities - Strategic Implementation Plan, [Online]. Available: https://www. interregeurope.eu/fileadmin/user_upload/tx_tevprojects/library/sip_final_en.pdf, 2013, [Accessed: 05-Aug-2021].

[70] European Commission, European Innovation Partnership on Smart Cities and Communities Operational Implementation Plan: First Public Draft, [Online]. Available: https://www.interregeurope.eu/fileadmin/user_upload/tx_tevprojects/library/ operational-implementation-plan-oip-v2_en.pdf, 2014 [Accessed: 06-Aug-2021].

[71] J., Wolf, M., Borges, J. L., Marques and E., Castro, Smarter Decisions for Smarter Cities: Lessons Learned from Strategic Plans, pp. 7-30, 2019.

[72] R., Giffinger, Smart cities Ranking of European medium-sized cities. October, 16, October, pp. 13-18, 2007.

[73] A., Ojo, Z., Dzhusupova and E., Curry, Smarter as the New Urban Agenda. Smarter as new urban agenda A Compr. view 21st century city, 11, August 2016, pp. 73-85, 2016.

[74] T., Monfaredzadeh and U., Berardi, How can cities lead the way towards a sustainable, competitive and smart future?. WIT Trans. Ecol. Environ., 191, pp. 1063-1074, 2014.

[75] T., Monfaredzadeh and U., Berardi, Beneath the smart city: Dichotomy between sustainability and competitiveness. Int. J. Sustain. Build. Technol. Urban Dev., 6(3), pp. 140-156, 2015.

[76] A., Sharifi and A., Murayama, A critical review of seven selected neighborhood sustainability assessment tools. Environ. Impact Assess. Rev., 38, pp. 73-87, 2013.

[77] ISO, ISO, [Online]. Available: https://www.iso.org/obp/ui/\#iso:std:iso:37120:ed-1:en, 2014, [Accessed: 02-Jun-2019].

[78] A., Sharifi, A critical review of selected smart city assessment tools and indicator sets. J. Clean. Prod., 233, pp. 1269-1283, 2019.

[79] A., Huovila, P., Bosch and M., Airaksinen, Comparative analysis of standardized indicators for Smart sustainable cities: What indicators and standards to use and when ?. Cities, 89, January, pp. 141-153, 2019.

[80] A., Stratigea, A., Leka and M., Panagiotopoulou, In search of indicators for assessing smart and sustainable cities and communities' performance, 6(1), 2017.

[81] P., Venkat Reddy, A., Siva Krishna and T., Ravi Kumar, Study on concept of smart city and its structural components. Int. J. Civ. Eng. Technol., 8(8), pp. 101-112, 2017.

[82] C., Etezadzadeh, Smart City - Future City? Essentials, 2016.

[83] HM, Treasury, Central Government guidance on evaluation, no. March. 2020.

[84] I. B., Huang, J., Keisler and I., Linkov, Multi-criteria decision analysis in environmental sciences: Ten years of applications and trends. Science of the Total Environment, 409(19) Elsevier, pp. 3578-3594, 01-Sep-2011.

[85] W. W., Cooper, L. M., Seiford and K., Tone, Data Envelopment Analysis: A comprehensive text with models, applications, references and DEA-solver software: Second edition. Springer US, 2007.

[86] F., Schuldt, A., Reschka and M., Maurer, Automotive Systems Engineering II. Automot. Syst. Eng. II, 2018. 